\title{
MIGRANTES EN CAMPAMENTOS: AUTOCONSTRUCCIÓN, ASPIRACIONES DE PERMANENCIA E INTEGRACION EN SANTIAGO DE CHILE
}

\author{
Migrants in Squatter Settlements: Autoconstruction, Aspirations for Long-Term \\ Stay And Integration in Santiago, Chile
} CRISTÓBAL PALMA \& MIGUEL PÉREZ*

Fecha de recepción: 20 de diciembre de 2019 - Fecha de aprobación: 10 de junio de 2020

\section{Resumen}

La presencia creciente de migrantes en las ciudades chilenas ha traído consigo el aumento sostenido del número familias extranjeras residiendo en "campamentos" (asentamientos autoconstruidos). De manera similar a las perspectivas clásicas sobre la autoconstrucción, su habitar en campamentos ha sido entendido principalmente como un "problema social", ya que agudizaría procesos de marginalización y exclusión social. Basado en una investigación etnográfica realizada en el campamento Nueva Esperanza de Colina, en el presente artículo afirmamos que, más que como un problema, los migrantes conciben el campamento y la autoconstrucción de viviendas como una alternativa que les permite responder a tres aspectos de su vida cotidiana: 1) necesidades habitacionales, 2) aspiraciones de permanencia en el país de destino y 3) deseos de imaginar formas distintas de integración urbana y social. Concluimos que un análisis antropológico del habitar migrante en campamentos nos permite explorar la agencia, la capacidad de creación y los reclamos espaciales de estos sujetos.

Palabras clave: campamentos; migración; permanencia; integración; autoconstrucción.

\section{Abstract}

The growing presence of migrants in Chilean cities has brought about a sustained increase in the number of foreign families residing in campamentos (autoconstructed squatter settlements). Similar to traditional approaches to autoconstruction, migrants' residency in campamentos has been mainly understood as a "social problem" as it would increase processes of marginalization and social exclusion. Based on an ethnographic study of the Campamento Nueva Esperanza in Colina, in this article we hold that migrants, rather than as a "problem," conceive of squatter settlements and the autoconstruction of houses as an alternative that allows them to deal with three aspects of their everyday life: 1) their housing needs; 2) their aspirations for long-term stay in the destination country; 3 ) their desires to imagine different forms of urban and social integration. We conclude that an anthropological analysis of migrants' residency in campamentos allows us to explore the agency, capacity for creation, and spatial claims of these subjects.

Keywords: squatter settlements; migration; long-term stay; integration; autoconstruction.

* Mtro. (c) en Sociología. Universidad Alberto Hurtado. Santiago, Chile. El artículo está enmarcado en el Proyecto Anillos "Etnografías del neoliberalismo y aspiración" (ANID PIA SOC180033) y al Centro de Estudios de Conflicto y Cohesión Social (ANID/ FONDAP/15130009).Correo-e: cristobal.spr@gmail.com

** Dr. en Antropología. Académico del Departamento de Antropología, Universidad Alberto Hurtado, Santiago, Chile. Correo-e: miguelperez@uahurtado.cl 


\section{Introducción}

Desde inicios de la década de 2010, el arribo sostenido de migrantes latinoamericanos a Chile ha resultado en un interés creciente de las ciencias sociales por analizar el fenómeno migratorio y sus implicancias. Entre otros aspectos, los autores han abordado temáticas tales como el carácter fundamentalmente feminizado de la migración, en especial a inicios del proceso (Mora, 2008; Stefoni \& Fernández, 2011); la falta de reconocimiento social y sus efectos en la construcción identitaria de los migrantes (Thayer, 2013); la estigmatización, la discriminación y el racismo al que se ven expuestos (Pavez, 2012; Tijoux, 2013); sus prácticas socioespaciales desplegadas en la ciudad y la "etnificación" del espacio urbano (Imilan, Garcés \& Margarit, 2014); el proceso de segmentación laboral en tanto expresión de su inserción precaria en la esfera productiva (Garcés, 2014; Staab \& Maher, 2006; Stefoni \& Fernández, 2011); las dinámicas particulares que adquiere la migración en ciudades fronterizas (Tapia, 2012; Valdebenito \& Guizardi, 2015); las formas de convivencia en barrios étnicamente diversos (Margarit \& Galaz, 2018), y los modos en que los migrantes acceden a la vivienda en áreas centrales de la ciudad (Contreras, Ala-Louko \& Labbé, 2015; Sheehan, 2018).

Sobre el aspecto residencial, algunos estudios han documentado prácticas extendidas de rechazo y discriminación habitacional hacia los migrantes, en especial respecto de quienes, por su color de piel o situación migratoria, están en mayor condición de vulnerabilidad (Thayer, 2013; Contreras et al., 2015; Sheehan, 2018). La precariedad y el abuso con los que conviven los migrantes se han profundizado con la consolidación de un mercado informal de arriendo y subarriendo destinado casi exclusivamente a grupos migrantes (Contreras et al., 2015; Curahua, 2013). En un contexto en que estos tienen dificultades objetivas para acceder a la vivienda formal, ha surgido un nuevo fenómeno asociado al aumento de migrantes latinoamericanos viviendo en asentamientos autoconstruidos o "campamentos" (López-Morales, Flores \& Orozco, 2018). En efecto, si en 2015 solo $6 \%$ de los residentes de campamentos a nivel nacional eran de origen extranjero (CIS-TECHO, 2015), en 2018 esa cifra aumentó a 27,4\% (Ministerio de Vivienda y Urbanismo, 2019). De manera relacionada, dicho fenómeno converge con el aumento, en la última década, del número de familias habitando en campamentos: de 27.378 en 2011 a 47.050 en 2018 (Ministerio de Vivienda y Urbanismo, 2019).

La mayor presencia de extranjeros en asentamientos autoconstruidos se da en un periodo de relativo desinterés de las ciencias sociales por caracterizar conceptual y teóricamente los campamentos ${ }^{1}$. Dicha desatención se explica por dos fenómenos concurrentes: primero, por el éxito de la política de vivienda basada en la asignación de subsidios, la que, en especial durante los años noventa, implicaron una reducción importante de los asentamientos informales en las grandes ciudades del país (Ducci, 1997; Márquez, 2004); segundo, la desactivación política de los movimientos de pobladores articulados en torno a tomas de terreno durante décadas pasadas (Angelcos \& Pérez, 2017). En este contexto, el crecimiento del número de familias viviendo en asentamientos informales, así como la diversificación étnica y nacional de estas, hace de este fenómeno una instancia privilegiada para repensar la función social de los campamentos en un Chile cada vez más heterogéneo. 
A mediados del siglo $\mathrm{XX}$, periodo en que los Estados nacionales latinoamericanos implementaron incipientes proyectos industrializadores, las ciudades de la región crecieron aceleradamente por el arribo de masas campesinas. En aquel entonces, el carácter problemático de los asentamientos autoconstruidos estuvo en el centro del debate académico. Algunas aproximaciones, articuladas en torno a la llamada teoría de la marginalidad (Vekemans, 1969; Vekemans, Giusti \& Silva,1970), pensaron los campamentos como un "área ecológica marginal" resultante de la imposibilidad de habitantes estructuralmente marginados para acceder e integrarse a la ciudad formal. Los campamentos eran vistos como un "problema" a resolver por los Estados nacionales pues, se decía, aglutinaban individuos "al borde de la incorporación objetiva [a la sociedad]", caracterizados por su atomización y falta de integración al colectivo social (Vekemans, 1969, p. 52). Dicho espacio residencial, pensaban algunos, sería un caldo de cultivo para proyectos radicales de izquierda o, en el peor de los casos, desembocar en formas de violencia inorgánica incontrolable (Vekemans, 1969; Bonilla, 1970).

Dicho enfoque marginalista fue fuertemente criticado por quienes vieron los campamentos como espacios altamente organizados, en los que sus residentes, lejos de estar atomizados, podían desarrollar nuevas formas de acción colectiva en su anhelo por vivir en la ciudad. Como concreción del derecho a la apropiación (derecho a usar, habitar y representar el espacio urbano) y el derecho a la participación (derecho a incidir en el proceso de toma de decisiones) que definiera Lefebvre (1996), los campamentos operarían como un catalizador de emergentes procesos de politización (p. ej., Castells, 1983; Giusti, 1973; Mangin, 1967; Perlman, 1976). Desarrolladas por "la acción autónoma de ocupantes de clase baja y de planificadores clandestinos" (Turner, 1968, p. 354), las ocupaciones de terrenos fueron vistas como determinantes en la transformación de los pobres en ciudadanos dotados de derechos. Mangin (1967) afirmaba que, más que un "problema", en América Latina los asentamientos informales aparecían como una "solución" práctica para quienes, incapaces de acceder a una habitación a través del mercado, concretaban su derecho a la vivienda a través de la autoconstrucción. Además, señalaba Mangin, estos asentamientos tendrían otras contribuciones a la vida urbana como, por ejemplo, ayudar a la urbanización de la periferia, dinamizar económicamente los márgenes de las ciudades y permitir la producción y multiplicación del capital social entre los pobres urbanos (Adler-Lomnitz, 1977).

Inspirados por estos últimos enfoques, en este artículo nos proponemos cuestionar las miradas marginalistas del campamento relevando la contribución práctica de estos espacios a la vida cotidiana de sus habitantes. El campamento es, ciertamente, un resultado objetivo de procesos estructurales de exclusión de grupos vulnerables que, por determinantes sociales y económicas, no pueden acceder a la vivienda formal, ya sea en propiedad o en arriendo. Durante gran parte del siglo $\mathrm{XX}$, tanto en Chile como en el resto de América Latina, el reconocimiento de los asentamientos informales como manifestación concreta de la exclusión movilizó a amplios sectores de la población, trayendo consigo la generación de políticas públicas enfocadas, de manera directa, en resolver la problemática habitacional (Angelcos \& Pérez, 2017). Pero la 
función social del campamento no se agota en encarnar residencialmente la desigualdad. En este artículo demostramos que los migrantes, aun reconociendo dichos procesos de exclusión, conciben el campamento como un espacio que les permite materializar tanto sus aspiraciones de permanencia en Chile como sus deseos de integración urbana y social. El campamento se constituye, entonces, como un tipo de habitación por medio de la cual los migrantes significan su condición de pobreza imaginando formas alternativas de inclusión. Desde este prisma, en este estudio buscamos actualizar la discusión teórica sobre este tipo de asentamientos en un contexto en que sus residentes no solo han crecido en términos cuantitativos, sino que también se han diversificado culturalmente.

Para reflexionar de manera crítica sobre el carácter puramente "marginal" y "problemático" de los campamentos, en este artículo discutimos tanto el "aquí" como el "allí" (Geertz, 1989); es decir, examinamos tanto las maneras en que se ha conceptualizado el hábitat informal y migrante como los significados que los propios actores asignan a su existencia en estos espacios. A partir de ese examen, mostramos que el campamento, aun cuando es socialmente concebido como un tipo de hábitat degradado y marginal, es imaginado por los migrantes latinoamericanos como una alternativa eficaz ante los problemas que acarrea el mercado formal e informal de arriendo. Esta alternativa es posibilitada por la autoconstrucción, práctica que va siendo delineada progresivamente a partir de nociones sobre lo que significa "vivir bien" y de las necesidades familiares de los migrantes. La autoconstrucción, afirmamos, permite la consolidación de un proyecto migratorio de permanencia que resulta limitado por las condiciones de lo que tradicionalmente se concibe como hábitat formal, dando espacio a formas históricamente situadas de integración de la población migrante a la sociedad chilena.

\section{Consideraciones metodológicas}

Este artículo nace de un proyecto de investigación etnográfica en el campamento Nueva Esperanza de Colina ${ }^{2}$, asentamiento formado por chilenos y migrantes en 2016. El trabajo de campo fue llevado a cabo durante ocho meses, entre 2017 y 2018 , periodo en el que realizamos observación participante. Al ser un campamento en formación al momento de nuestro arribo, este método nos permitió conocer las formas de ocupación del espacio desplegadas por los migrantes, así como el modo en que autoconstruían su barrio y sus viviendas. Además, realizamos 30 entrevistas en profundidad a migrantes, principalmente de origen dominicano, haitiano, colombiano y boliviano. Los entrevistados fueron seleccionados siguiendo un tipo de muestreo no probabilístico (técnica de "bola de nieve"). El material textual proveniente de entrevistas y notas de campo fue analizado mediante la "teoría fundamentada" de Glaser y Strauss (2017), proceso interpretativo de carácter inductivo en el cual los datos empíricos organizan y determinan las reflexiones teóricas aquí expuestas. 
Asentamientos informales y hábitat migrante como un problema de integración

Las formas de habitar que han excedido la racionalidad planificadora de la ciudad, sea esta dirigida por el Estado o el mercado, han sido tradicionalmente consideradas como problemáticas. Tanto los asentamientos informales como las prácticas espaciales de los migrantes parecen encarnar dos formas concretas de transgresión a las formas hegemónicas con que la planificación urbana concibe el uso y la ocupación del espacio urbano; transgresión que ha tenido eco en cómo las ciencias sociales han abordado dichos fenómenos para reflexionar sobre la integración.

El hábitat denominado informal, en cuanto encarnación de "problemas" o "patologías" sociales, ha sido leído como expresivo de los límites o debilidades del Estado para garantizar servicios y bienestar a las capas más excluidas (Vekemans, 1969; Dromi, 1987; Matos Mar, 1984). En términos simbólicos, el campamento, como espacio diferenciado del resto de la ciudad, ha sido visto como anverso ineludible del progreso, la movilidad social y la integración social de sus habitantes (Morales, Besoain, Soto, Pinto, Hidalgo, Fernández \& Bernal, 2017; Abufhele, 2019). De manera paralela, la preocupación por la integración y la conformación de barrios segregados ha sido un eje central en los estudios migratorios. Desde los análisis pioneros de la Escuela de Chicago, la concentración de población migrante ha sido principalmente pensada bajo las figuras de enclave o gueto. Aunque con matices, tales conceptos remiten a un espacio que, si bien funciona como instancia de "acomodación” para los migrantes (Wirth, 1982, p. 289), al mismo tiempo concentra una serie de problemas sociales derivados de su carácter segregado, el que promovería la existencia aparente de mundos separados de la sociedad nacional (Alexander, 2011; Tonkiss, 2005).

El hábitat informal, más aún cuando es practicado por migrantes, ha sido mayormente pensado como reflejo espacial de la desigualdad social. Los asentamientos autoconstruidos son representados como escenarios de miseria, pobreza y depravación, susceptibles de ser evaluados en relación con su par contrario, el hábitat formal, donde la población —decía Vekemans (1966) a mediados del siglo XXvive con "niveles casi europeos". Esta mirada de los campamentos no ha estado ajena a la crítica. Algunos autores han planteado que su carácter "informal" resulta no de la pobreza misma, sino de la desigualdad de poder entre las fuerzas negociadoras de gobiernos y habitantes para organizar las maneras de habitar la ciudad (ver, por ejemplo, De Soto, 1987; Brain, Prieto \& Sabatini, 2010; Caldeira, 2017). No obstante, la comprensión del campamento como reflejo de la desigualdad social y como espacio de marginalidad — mirada de herencia desarrollista, modernizante y colonial (Varley, 2013)— continúa teniendo eco a la hora de pensar estos asentamientos como un "problema" para la integración. Un ejemplo de ello es el concepto de "campamentación” (López-Morales et al., 2018, p. 165), que concibe el aumento del número de familias viviendo en campamentos como consecuencia de un proceso de desafiliación social y exclusión de la sociedad mayor. La "campamentación", por tanto, estaría caracterizada por la existencia de sujetos en situación de vulnerabilidad y pobreza que, frente a contingencias económicas que les impiden cubrir gastos en vivienda, optarían forzosamente por vivir en "situación de campamento" (López-Morales et al., 2018, p. 166). 
Este prisma ha dominado en las pocas investigaciones que, en la última década, han analizado la presencia creciente de migrantes en los asentamientos autoconstruidos en Chile. Campos (2017), por ejemplo, arguye que el arribo de migrantes latinoamericanos a los campamentos está relacionado con la precarización del empleo y con su vulnerabilidad. Su llegada a estos espacios, por tanto, estaría asociada a una serie de condiciones de precariedad que, sumada a factores detonantes como la pérdida de empleo, rupturas familiares o situaciones económicas desfavorables, propicia la vida en asentamientos informales (CIS-TECHO, 2018; López-Morales et al, 2018). Estas interpretaciones han vuelto a poner el dualismo formal/informal $-\mathrm{y}$ su par integración/desintegración- como el eje analítico de mayor rendimiento explicativo para dar cuenta de este fenómeno. López-Morales et al. (2018) señalan, en tal sentido, que "el resurgimiento de la vida en campamentos en el país muestra la dualidad entre exclusión y posibilidades de integración" (p. 182). Con ello, sugieren que la integración solo es posible desde la inserción de los migrantes en la ciudad "formal". La residencia de migrantes en campamentos, una "forma de desplazamiento urbano por exclusión social" (López-Morales et al., 2018, p. 183), sería, entonces, principalmente involuntaria y producto de fuerzas sociales ajenas al poder de decisión de sus protagonistas.

En cuanto a los análisis del hábitat migrante, la concentración y la segregación etnonacional de población migrante en áreas específicas de la ciudad continúan siendo examinadas como un escollo para la integración de estas poblaciones en sociedades receptoras. Aunque algunos trabajos han demostrado que los espacios de concentración de población migrante no consti- tuyen necesariamente formas de segregación al operar como escenarios de encuentro y pivote de movilidades sociales y espaciales (Alexander, 2011, en Inglaterra; Márquez, 2014, en Chile; Perissinotti, 2016, en Argentina), en Chile la emergencia de barrios de migrantes ha sido mayormente pensada como un problema social. Esto queda de manifiesto en trabajos como los de Margarit y Bijit (2014), quienes advierten que la aglomeración espacial de extranjeros, descolgada de la dinámica social de la ciudad, puede decantar en la generación de guetos de inmigrantes. Asimismo, Jiménez (2016) argumenta que, en los barrios populares, se estaría asistiendo a formas de guetización o "preludios" a guetos migrantes, debido a la "uniformidad" racial y cultural de sus habitantes. Dicho proceso los colocaría en una situación de segregación socioespacial que, además de facilitar la reproducción de la pobreza, limitaría el acceso a los beneficios que la ciudad, idealmente, otorga a todos sus habitantes.

Pensar los campamentos y el hábitat migrante como problemas sociales ayuda, ciertamente, a denunciar la desigualdad social, así como a proponer alternativas de solución en el ámbito de la política pública. Sin embargo, como recuerda el antropólogo Leonardo Piña (2010), el principal riesgo de estas maneras de enunciar contenidos es que, al exponerlas, se renuncia también a otras formas de enunciación. En ese sentido, creemos que las investigaciones contemporáneas sobre el hábitat informal y migrante en Chile han renunciado a considerar estos procesos de agrupamiento étnico-nacional y de vida en asentamientos informales como producto y resultado de la agencia y las capacidades de creación y reclamo espacial de sus habitantes (Alexander, 2011) ${ }^{3}$. Ello, a pesar de que antropólogos y planificadores 
urbanos ya han reparado en el papel preponderante de los pobladores en la edificación de las ciudades latinoamericanas y del Sur global (Caldeira, 2017; Holston, 2008; Varley, 2013; Skewes, 2005). Asimismo, otros han relevado las prácticas, experiencias y acciones de las personas migrantes en la construcción y la modificación de las espacialidades de la ciudad (Márquez, 2014; Alexander, 2011; Perissinotti, 2016). Tomando en consideración dichas perspectivas, en lo que sigue discutiremos el carácter de "problema" de los asentamientos informales migrantes a la luz de las prácticas y los discursos de sus propios moradores, en diálogo con postulados teóricos que reconocen la relevancia de las agencias migrantes.

\section{El campamento Nueva Esperanza}

Nueva Esperanza fue formado el año 2016 por un grupo de chilenos y migrantes que ocuparon un predio de aproximadamente una hectárea en Colina, en las inmediaciones del Centro Penitenciario Colina II. El campamento está rodeado por barrios de clase media-baja y baja, la mencionada cárcel, el cementerio comunal y un sitio eriazo, por el que se accede directamente a la avenida General San Martín, arteria principal de la comuna. Hacia el este del campamento, al cruzar por un área residencial popular, se ubica el estero Colina. A pesar de que el curso hídrico está a menos de 200 metros de Nueva Esperanza, nunca obtuvimos referencias directas en torno a su potencial riesgo.

La comuna de Colina, aunque se localiza en la extraperiferia de Santiago, concentra una actividad comercial y laboral dinámica por la presencia de condominios para familias de la elite en el sector de Chicureo. Es justamente este dinamismo el que ha atraído a migrantes a la comuna, los que sumaban 15.075 según datos del último Censo de 2017. A diferencia de otras comunas de la región, donde residen principalmente migrantes de origen venezolano, peruano y colombiano, en Colina la mayor parte de los residentes de origen extranjero son haitianos $(19,6 \%)$ y dominicanos (18,2\%) (INE, 2018).

Mientras la mayoría de las mujeres migrantes que vivían en el campamento trabajaban en el servicio doméstico, otras lo hacían en fábricas y comercios, como obreras y vendedoras. En cuanto a los hombres, existía algo más de diversidad. Algunos se dedicaban a la construcción, otros trabajaban en jardinería, en talleres mecánicos o como guardias de seguridad. No muchos migrantes del campamento se empleaban informalmente o por cuenta propia. Quienes lo hacían frecuentaban las ferias y los mercados informales circundantes a la avenida General San Martín. Además, pudimos observar algunas mujeres que tenían pequeños negocios dentro del campamento, donde comerciaban abarrotes, cigarrillos y cervezas. En otros se ofrecían almuerzos de manera esporádica o se prestaban servicios de embellecimiento (arreglo de uñas, cortes de cabello, etc.).

En concordancia con la realidad migratoria de la comuna, la mayoría de los habitantes eran de origen dominicano y haitiano. En menor medida, residían también bolivianos, peruanos, colombianos y chilenos. Estimaciones hechas por las dirigentas del campamento señalan que, hacia fines de 2017, en la ocupación vivían aproximadamente 80 familias. No obstante, resultaba difícil especificar el número efectivo de familias residentes ya que, al momento de realizar el trabajo de campo, persistía la llegada de nuevas personas. Junto a ello, fue común 
observar la subdivisión de terrenos previamente loteados (Imagen 1), con lo que aumentaba tanto la cantidad de habitantes como la densidad residencial del campamento. Todas las viviendas contaban con luz eléctrica, obtenida de manera gratuita mediante conexiones irregulares al alambrado público. En el caso del agua, accedían a ella mediante cañerías anexadas al suministro de agua potable desde una casa contigua al campamento, cuyo residente cobraba alrededor de 10.000 pesos mensuales por vivienda.

Nuestros interlocutores afirmaban que fueron los chilenos los primeros en llevar a cabo el trazado de calles y el loteo de los sitios. Al inicio, cada sitio fue marcado con un número, muchos de los cuales hoy sirven para identificar cada vivienda. El trazado de calles al interior del campamento siguió la forma de un plano ortogonal, con tres calles principales y cuatro pasajes interiores. Cada terreno es diferente en relación a su contiguo, en cuanto a cantidad de metros y forma. El acceso al suelo urbano fue diferenciado para chilenos y migrantes. Para autoconstruir sus viviendas, la mayoría de los entrevistados de origen extranjero debieron pagar sumas que oscilaban entre los 80.000 y 400.000 pesos a los chilenos que iniciaron la ocupación. Como señala Alexis, migrante dominicano de unos 38 años, "nosotros los extranjeros no nos metemos en tomas, a nosotros nos venden, nos meten [en la ocupación]". Esta cita demuestra que las lógicas de acceso a campamentos han cambiado. Si en el pasado el solo hecho de "ser chileno" habilitaba en términos político-morales para la ocupación de un espacio (Espinoza, 1988), en la actualidad los migrantes muchas veces deben pagar esta especie de "derecho de admisión" para poder formar parte del campamento. Si bien esto puede ser visto como una forma de discriminación, los migrantes tendían a considerarlo como una forma legítima de acceder a la propiedad del terreno que ocupaban, aun sabiendo que la compra era de carácter informal.

En materia de edificación de las viviendas, pudimos observar que, en la mayoría de los casos, la autoconstrucción era llevada por los mismos residentes. No obstante, cuando nuestros interlocutores reconocían no disponer de las competencias necesarias para esa tarea, esta era realizada por otros sujetos - generalmente hombres que vivían dentro del campamento- a cambio de un pago. En cuanto a los montos destinados a la construcción, todos dijeron haber gastado entre 2.000.000 y 4.000.000 de pesos. Esa cifra probablemente aumente ya que, en opinión de los entrevistados, el proceso de autoconstrucción, más que acabado y finito, se prolonga en el tiempo según la necesidad de acomodar la casa a los deseos de permanencia en el país. Todo ello hacía de este asentamiento un paisaje bastante diverso en cuanto a tipologías de viviendas, acabado y decoración de interiores; diversidad que concebimos como encarnación de los distintos proyectos de vida y disposiciones morales que orientan la cotidianidad de sus habitantes.

En términos estructurales, la mayoría de las casas compartían materiales de edificación como los tableros de madera aglomerada (OSB) y techos de zinc (Imagen 1). Sin embargo, al observar con mayor detalle, pudimos dar cuenta de una serie de elementos en cuanto al acabado de las viviendas y ciertas diferencias estéticas, sobre todo en relación con las viviendas de chilenos y migrantes. Mientras que las familias chilenas tendían a construir de manera mucho más rudimentaria y poco sofisticada, las familias 
migrantes parecían más dedicadas y comprometidas con la decoración de sus espacios residenciales, cuestión que se vuelve patente al comparar los materiales usados en puertas, pisos, rejas, etc. Por ejemplo, una buena parte de las viviendas de las familias migrantes había acondicionado sus pisos con radier de cemento y cerámica, a diferencia de las de las familias chilenas, que tenían piso de tierra. Asimismo, la mayoría de las viviendas de migrantes contaban con material de aislación del frío, como vulcanita, en sus paredes. En un inicio, consideramos que estas diferencias estéticas en la autoconstrucción respondían únicamente a la desigual capacidad económica de chilenos y migrantes. No obstante, posteriormente notamos que, a través de la autoconstrucción, los migrantes buscaban realizar materialmente sus nociones de lo que significa "vivir bien"; ideas y sentidos que estaban directamente relacionados con sus "malas" experiencias residenciales anteriores y la necesidad de tener un lugar para poder instalarse de manera definitiva en el país.

Imagen 1. Subdivisión predial en Nueva Esperanza, en donde se exhibe la materialidad de murallas y techumbres.

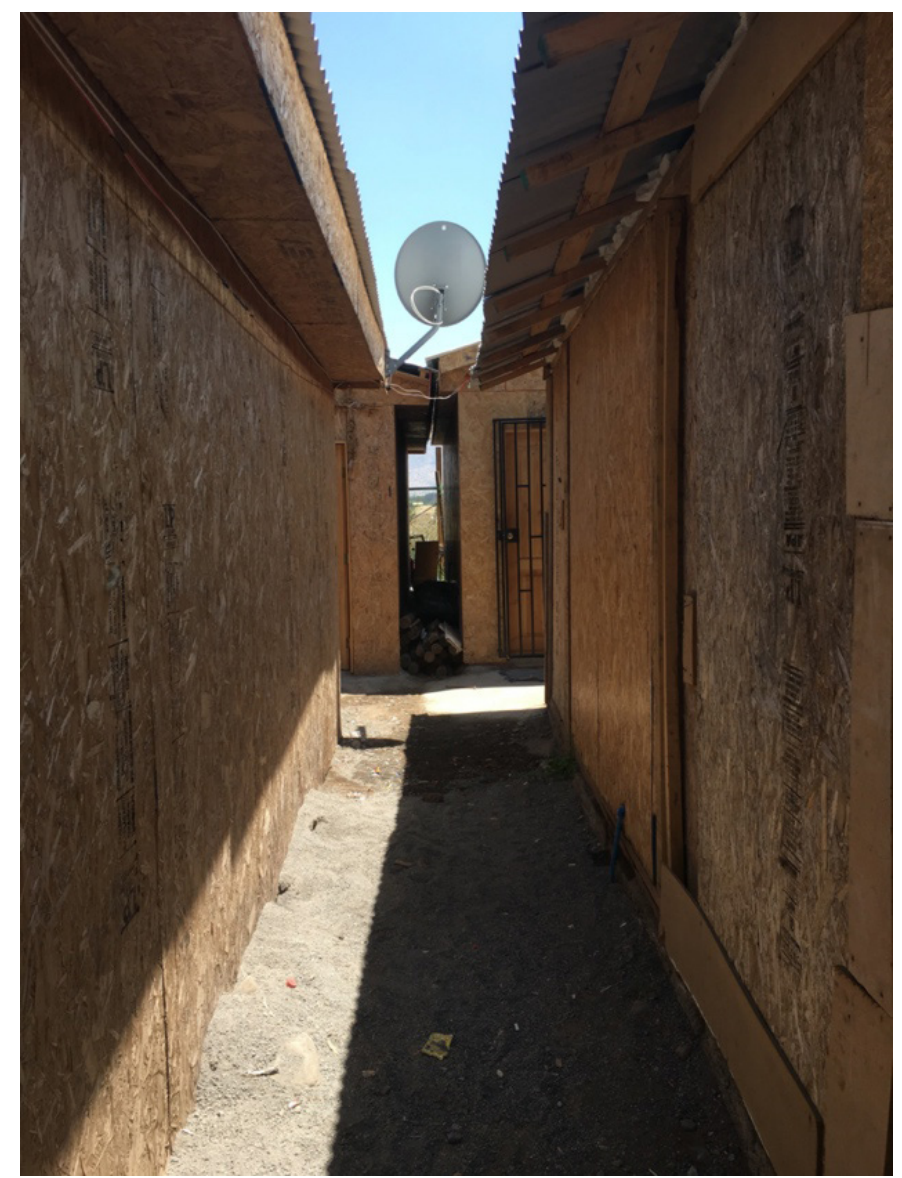

Foto tomada por Miguel Pérez, diciembre de 2017. 


\section{"Feas, malas y chicas": las viviendas fuera de Nueva Esperanza}

Trabajos recientes han documentado, de manera extensiva, las condiciones abusivas y discriminatorias a las que se enfrentan los migrantes latinoamericanos al momento de buscar una vivienda en Santiago y las grandes ciudades del país. Dichas prácticas operan tanto en el mercado formal como en el informal, ya sea mediante el arriendo legal (con contrato) o a través de formas de subalquiler de piezas en cités o viviendas compartidas (Contreras et al., 2015; Curahua, 2013; López et al., 2018; Sheehan, 2018). Prácticamente la totalidad de las personas que entrevistamos en Nueva Esperanza dijeron haber tenido una o más experiencias residenciales en casas de arriendo en Colina, específicamente en poblaciones y villas de viviendas sociales aledañas al sector donde hoy se ubica el campamento. Estas fueron construidas durante las últimas décadas para albergar a población de bajos ingresos, mediante la modalidad de subsidio habitacional. La presencia dinamizadora del mercado de arriendos que ha generado la migración latinoamericana trajo consigo una alta demanda por el alquiler de viviendas subsidiadas. En ese escenario, se ha producido un alza de precios que hace oscilar los aranceles entre 80.000 pesos por una pieza, hasta 300.000 por un departamento en un block de vivienda social o una casa de tres o cuatro habitaciones. Esto dista mucho de los 50.000 y hasta 200.000 que Lady, migrante dominicana, señalaba que costaban los arriendos cuando llegó a vivir a la comuna a inicios de la década.

Sin embargo, el principal problema con respecto al mercado de arriendo de viviendas, según las y los entrevistados, no tiene que ver únicamente con su valor monetario, sino también con una suerte de economía moral de naturaleza compartida, como la entiende el antropólogo francés Didier Fassin (2015). Fassin concibe la economía moral como la producción, circulación y apropiación de normas, obligaciones y afectos relativos a un problema -en este caso, la calidad de la vivienda- en un tiempo y espacio específico. En ese sentido, para nuestros interlocutores, la provisión de una vivienda en arriendo involucra tanto la transacción de un inmueble como el aseguramiento de ciertas condiciones de calidad y seguridad que se espera entregue esa transacción y que les permita "vivir bien". Es justamente este "vivir bien" el que no estaría garantizado en el mercado privado de vivienda y lo que activa el cuestionamiento moral hacia las condiciones de las moradas que este ofrece.

Los testimonios de nuestros entrevistados fueron elocuentes al respecto. En repetidas ocasiones nos hicieron saber la falta de mantención y los problemas de habitabilidad de las viviendas que arrendaban previo a su llegada al campamento. Entre otros problemas, mencionaron haber habitado en casas con techumbres con filtraciones, pisos derruidos, llaves con goteras, paredes sin pintar, malos olores en los baños y otros descuidos. El testimonio de Luisa, migrante dominicana de 40 años, es ilustrativo al respecto, pues retrata los efectos familiares que ocasionó vivir en una vivienda en mal estado:

\footnotetext{
Mi hija [se refiere a su hija mayor] volvió [a República Dominicana]; no le gustó aquí. Ella dijo, "mami, yo quiero experimentar, a ver cómo es Chile"... Entonces, lo que ella hizo fue que se fue... la casa donde yo vivía era un caos. Ella tenía que dormir en el living, porque cuando llovía imagínate la vulcanita. Esa vulcanita le caía agua de arriba y eso se abombaba. Se cayó el techo de la habitación de la muchacha.
} 
Sumado a ello, emergieron testimonios que dan cuenta de la inseguridad permanente en el arriendo. La más recurrente se vinculaba a experiencias de desalojo que sufrieron algunos migrantes, ya que las viviendas en que residían habían sido hipotecadas o vendidas a otros dueños, aun cuando ellos eran arrendatarios. Darcy, migrante dominicana de 38 años, señala:

La casa donde nosotros vivíamos, el dueño como que la tenía hipotecada. Porque ya llegaban muchos papeles, de que iban como a embargar la casa. $Y$ nosotros le llamamos y le preguntamos, "oiga Héctor y qué pasa con el tema de la casa"... [Dijo] que supuestamente era mentira que se la embargaban. Pero esos papeles llegaban todos los meses, porque la casa estaba embargada.

A partir de situaciones como estas, los migrantes identificaban a sus arrendadores, en su mayoría chilenos de clase baja, como "sinvergüenzas" e incluso "delincuentes". Bajo sus relatos, los arrendadores buscan "aprovecharse" y "hacerse ricos" a través de este negocio, no importándoles la calidad de vida de los arrendatarios. Esto permite la construcción de un cuestionamiento moral común en relación con la calidad de la vivienda que habitaban antes de llegar a Nueva Esperanza. Ninguno de nuestros interlocutores tematizó estas experiencias como una forma explícita de racismo o discriminación por el carácter migrante de los arrendatarios. Más bien, puntualizaron criterios morales asociados a conductas que resultan éticamente reprochables, tal como ejemplifica el diálogo sostenido con Luisa en agosto de 2017, registrado en las notas de campo:

Al entrar al campamento nos encontramos con Luisa, quien está visiblemente ofuscada. Al medio de la calle conversamos y nos relata que vino a buscarla su anti- gua arrendadora de la villa que está al otro lado de la Av. General San Martín y que quería cobrar una plata que, según ella, le adeudaba. Luisa dice que esa mujer es una "viciosa" y que sus familiares son todos "delincuentes". Agrega que vino a armarle un escándalo mientras ella no estaba. Luisa dice que ya tuvo que pagarle una vez porque no quiere tener problemas con ella y que esta es segunda vez que le hace una visita al campamento para pedirle dinero de la antigua casa que arrendaba en la comuna. Nos cuenta que es frecuente que los migrantes tengan problemas con sus arrendadores, porque casi todos los acuerdos son de palabra y esto permite que los arrendadores se aprovechen y quieran conseguir más dinero. (Notas de campo)

Visto así, las condiciones de arriendo en cuanto a precio, calidad y seguridad, sumado a relaciones hostiles y de desconfianza sobre los arrendadores, hace que la experiencia de acceso a la vivienda formal en arriendo sea cuestionable, en términos morales, y que colisione directamente con las expectativas de "vivir bien" que traen los migrantes en su arribo al país. Esta disconformidad es referida a través de expresiones como "yo me cansé de arreglar [la vivienda]", "a mí me dio una depresión", "ya no quería pasar más trabajo" o "uno no haya pa' dónde ir". Sumado a ello, los espacios de la vivienda en alquiler dificultan considerablemente las posibilidades de comenzar un proceso de consolidación y permanencia en el país, que implica formas de reunificación o recomposición familiar nuclear o extensa. Si arrendar una pieza o una casa con uno o más conocidos parece ser una buena solución durante un lapso, a medida que comienzan a migrar también los familiares de quienes se van avecindando en el país, o se conforma un proyecto de familia nuclear entre migrados, las viviendas van haciéndose más pequeñas y emergen roces cotidianos entre conocidos y familiares que hacen difícil la convivencia. 
La mayoría de los migrantes que participaron en la investigación comenzó llegando a la casa de un conocido o familiar $y$, al pasar de los meses, tuvo que arrendar su propia casa. Así lo demuestra el testimonio de Juan Luis, migrante dominicano de 45 años, y Rony, migrante haitiano de 40 años:

[Mi hermana] vivía allá, ella alquilaba [en una villa aledaña]. Vivíamos arrendado ahí... Pero entonces no cabíamos ya... Ella tenía sus hijos. Entonces ahí mismo llegó una hija de ella y yo tuve que buscar dónde vivir. (Juan Luis)

[Encontré] un amigo que arrendaba uno [departamento], entre ellos dos, y cuando yo llegué, lo pagamos entre tres hasta que el dueño del apartamento necesitaba su apartamento y nosotros nos separamos. Yo arrendé otro y ellos cada uno arrendó otro, porque tienen sus familias que han entrado [a Chile]. (Rony)

Cuando los migrantes deciden permanecer en el país comienza, en la mayoría de los casos, un proceso de "mandar a buscar", en palabras de Cecilia —una migrante dominicana- a los hijos y otros parientes para establecerse. Los procesos de recomposición y/o reunificación familiar implican una serie de transformaciones en la estructura misma de la familia, de las necesidades habitacionales y el presupuesto familiar (Rivas, 2013). Esto queda de manifiesto, ilustrativamente, en el testimonio de Raimundo, migrante boliviano de unos 35 años:

Yo vine solo para ver si había posibilidades o no. Entonces vine yo solo y después de un año los traje [a su familia]. Conseguí por lo menos arrendar una casa pa' traerlos... Era chica, no tan grande. Era muy incómoda, porque igual se pagaba el arriendo, todo eso, y la casa era un poco chica. O sea, era una casa, pero partida a dos, compartíamos dos familias.
Así como Raimundo, Luisa recuerda que debió mudarse a una casa que costaba alrededor de 250.000 pesos, y que, en sus palabras, "era un prieto de casa eso", refiriéndose a que la vivienda era muy ajustada, pequeña y dificultaba la convivencia entre ella, sus dos hijas y su hermano. En síntesis, los testimonios y experiencias de los migrantes que habitan actualmente en Nueva Esperanza muestran que el acceso a viviendas en arriendo, sea o no con contrato de alquiler, presenta una serie de dificultades que no tienen que ver exclusivamente con su costo, sino también con otras cuestiones relacionadas con la calidad y la seguridad en la tenencia, las relaciones hostiles con los arrendadores y la imposibilidad de acomodar las necesidades familiares y los proyectos de permanencia en el país. Como se verá a continuación, el campamento emerge, en la voz de sus propios habitantes, como una alternativa viable para resolver gran parte de estos problemas.

\section{El campamento como alternativa residencial}

Luisa vivía en Nueva Esperanza con su pareja de nacionalidad chilena, un hijo adulto y su hija menor. Todos los miembros de la familia participaron en la construcción de la vivienda, la que tenía planchas de madera de OSB (madera aglomerada de bajo costo) en las murallas y techo de zinc. El piso era de cemento y contaba, además, con desayunador americano, televisión, equipo de música, un cómodo living-comedor y paredes interiores adornadas de recuerdos y fotografías de su familia. Luisa llegó a Chile hace 7 años. Su trayectoria residencial habla de un constante éxodo entre arriendos de casas en la comuna y 
la búsqueda permanente de un lugar para poder traer a su familia desde República Dominicana. De todos los lugares en que ha residido, el campamento es el que más la acomoda. "Esto está mejor que todas las casas a las que yo me he mudado", nos dijo cuando le preguntamos cómo evaluaba sus condiciones de vida en Nueva Esperanza.

Para Luisa, al igual que para muchos otros de nuestros interlocutores, el campamento emerge primeramente como una alternativa y una solución ante las dificultades que acarrea vivir como arrendatario. Para ellos, resulta un alivio dejar de pagar arriendo por una vivienda que, en general, es de precarias condiciones: "Sabes la plata que yo he me ahorrado de pagar alquiler", dice Cela. El dejar de pagar arriendo, sin embargo, no es visto solo como un ahorro, sino también como una "inversión". Como señalamos arriba, la mayoría de los residentes de origen migrante pagaron por su derecho a usar un terreno. Además, debieron conseguir materiales, en algunos casos mano de obra para la construcción, y bienes de consumo para adornar sus nuevas casas. Alejandro, un migrante dominicano de unos 40 años, estima en más de 4.000.000 de pesos lo gastado entre la obra gruesa, el terreno y el equipamiento de su vivienda. Como otros, consiguió recursos tanto de familiares como mediante préstamos de sus empleadores, que les fueron descontados mensualmente del salario. Para él y para sus vecinos, vivir en el campamento, si bien irregular y precario en términos de la tenencia, los dotaba de un sentido de posesión, ya que les permitía realizar sus expectativas residenciales de forma autónoma, lejos de la vulnerabilidad del arriendo.
En la medida en que vivir en Nueva Esperanza otorga un sentido de posesión, emerge un segundo elemento que alimenta la percepción del campamento como alternativa, a saber, las condiciones de seguridad que facilita. Alexis señala que "compramos [el terreno en el campamento] para tener algo seguro donde uno sabe que ya no le van a pedir la casa". La mayoría de los entrevistados y las personas con las que compartimos durante la investigación opinó de manera similar. A pesar de los rumores que, de vez en cuando, circulaban sobre la posibilidad de un desalojo, los habitantes de Nueva Esperanza tenían la convicción de sentirse más seguros viviendo en un asentamiento informal que en una casa en arriendo, ya que, como señaló una residente dominicana, "no se sabe cuándo se la van a pedir a uno [la vivienda]".

Asociado a lo anterior, un tercer elemento que el campamento, en opinión de sus residentes, resuelve son los problemas en torno a la calidad de la vivienda en arriendo. Como mencionamos anteriormente, los migrantes que viven en Nueva Esperanza manifestaban extendidamente su disconformidad con la calidad de las viviendas a las que podían acceder en el mercado privado. En ese sentido, el proceso de autoconstrucción permite una mejora continua de los espacios residenciales (Caldeira, 2017) bajo la idea de que, a través de las transformaciones materiales en la vivienda, se puede realizar el "vivir bien". La idea de "vivir bien" queda demostrada en las palabras de Alexis:

\footnotetext{
Pasa que nosotros tenemos otro tipo de costumbres. A nosotros [los migrantes] nos gusta estar cómodos... nos gusta tener nuestro espacio, ¿comprende? Por ejemplo, tener una radio, tener donde sentarse. A nosotros nos gusta tener nuestro espacio, vivir más tranquilos, ¿comprende?
} 


\section{De la autoconstrucción al proyecto de permanencia}

La autoconstrucción, señala Caldeira (2017), involucra una temporalidad específica organizada por la constante renovación del espacio construido. Las casas y los barrios, señala la autora, crecen gradualmente en un proceso de largo alcance, en el que los residentes mejoran sus espacios residenciales de forma continua hasta urbanizar amplias áreas de las ciudades $e$ integrarse de lleno a estas. Para los migrantes, es justamente la autoconstrucción -y su capacidad de acomodar nuevas necesidades familiares- la que encarna la noción de "vivir bien" descrita más arriba y, en consecuencia, sus anhelos de permanencia. En su trabajo sobre el caso argentino, María Victoria Perissinotti (2016) ha destacado que los migrantes internacionales articulan proyectos de permanencia e integración social mediante luchas políticas por el acceso y la mejora del espacio urbano desde los asentamientos informales. En línea con dicho argumento, afirmamos que la autoconstrucción de las viviendas, y las posibilidades de mejora continua que esta permite y promueve, se presenta como una forma de articular aspiraciones de permanencia e integración en el país por parte de los extranjeros que habitan en campamentos.

En Nueva Esperanza, esta autoconstrucción se da de manera individual/familiar más que colectiva, en contraste a lo que ha sido largamente descrito en otros periodos de la historia política chilena ${ }^{4}$. Independientemente de su carácter en apariencia menos reivindicativo, el caso de Nueva Esperanza ilustra de manera clara la creciente importancia de la significación contemporánea de la autoconstrucción para quienes deciden hacer de Chile su país de residencia. Las experiencias de Raimundo y Cela nos ayudarán a ilustrar la relación entre autoconstrucción y proyectos de permanencia.

Raimundo es boliviano. Vive hace más de 6 años en Chile con su esposa, también boliviana, y sus dos hijos pequeños. Su casa en el campamento es bastante amplia; cuenta con ventanas y antejardín. En una de nuestras visitas, observamos en el patio a su pequeño hijo jugando con dos perros cachorros, uno blanco y otro negro. Raimundo dice que los eligieron así por el equipo de fútbol Colo Colo. Hasta antes de llegar al campamento, Raimundo vivía en una villa aledaña al sector. Según nos cuenta, la casa era pequeña, incómoda, sin luz, ni aire. Dice que sus hijos no podían salir a jugar. Desde que están viviendo en el campamento, "los chicos juegan, saltan y corren entre la gravilla y el polvo del antejardín". Raimundo cuenta que difícilmente volverá a Bolivia, quizás de visita. Señala que se ha hecho grandes amigos chilenos que le ayudaron a levantar el techo de su casa. El resto lo construyó con sus propias manos. Aún le faltan muchas cosas por hacer, dice: "siempre hay algo por mejorar". Sin embargo, manifiesta estar tranquilo y feliz en el campamento. "Por mí que me dejaran [acá]".

Cela es una adulta mayor de origen dominicano. Llegó a Chile hace más de seis años en solitario a trabajar en el servicio doméstico en el sector de Chicureo. Cela fue de las primeras mujeres extranjeras en llegar al campamento. Pagó por el terreno como la mayoría de los migrantes que viven en Nueva Esperanza. También tuvo que pagar por construir su vivienda, ya que no tenía conocimientos en el área y su pareja, un chileno que conoció en Colina, "es un poco flojo". La casa de Cela posee un antejardín de aproximadamente 7 
metros cuadrados. En él hay algunos sillones, sillas, incluso una gran piscina de plástico en la que alguna vez nos bañamos durante el trabajo de campo. Además, hay muchas plantas, en específico cactus y suculentas de diferentes variedades, ubicados en unas bancas que dan directamente a la calle. "Así la voy poniendo bonita", dice. La vivienda cuenta con un living-comedor de al menos 5 metros de largo por 10 de ancho. También posee una cocina bastante amplia. La casa cuenta con cinco piezas y en ella viven "dos familias": ella, su pareja y su hijo menor, de unos 30 años, que acaba de llegar desde República Dominicana, y la familia de su hija mayor.

Como se refleja en estas historias, nuestros interlocutores imaginan la autoconstrucción no solo como solución a la precariedad de la vivienda en arriendo, sino también como un medio para reunificar y reconstruir sus familias en Chile. Ya sea pensando en los hijos pequeños o en la edificación de una casa amplia para albergar a toda la familia que ha migrado, la autoconstrucción muestra que el diseño informal resulta mucho más flexible ante la diversidad de necesidades que presentan las familias en el campamento (Skewes, 2005). Adicionalmente, el hecho de construir una vivienda permite el desarrollo de lecturas críticas o "justificaciones", en el sentido de Boltanski (2012), que permiten reafirmar el derecho a permanecer en el lugar como parte de un proyecto familiar de permanencia en el país. Tal es el caso de Eduardo, quien, al indagar sobre la manera en que legitimaba su derecho de permanencia en el país en tanto extranjero, señaló lo siguiente: "Sí [tengo derecho a quedarme en Chile]. Porque tengo familia, mis hijos más que todo. Porque tengo que ver el velar de ellos, para tener un techo donde dormir".
Tener un modo de justificar la presencia en el lugar por haber construido una casa y tener el derecho a una casa por tener una familia, se presentan como aspectos claves que otorgan la posibilidad de afirmar aspiraciones de permanencia para los migrantes de Nueva Esperanza. Así, el anhelo de quedarse en Chile se articula, de igual manera, con continuar viviendo en el campamento. Por ello, una buena parte de sus habitantes aspira menos a tener una vivienda subsidiada en otro barrio que a regularizar el terreno en el que viven para continuar mejorando progresivamente sus casas. Así lo señalan Antonio y Larisa:

Cómo le digo, [la casa] ya está construida, si un día nos aceptan y nos dejan aquí, yo me haría una casa, esta la construiría en una casa mejor. Trabajaría, la reforzaría en otro material. (Antonio)

Bueno, mira, el gusto mío es que me dejaran aquí [en el campamento] porque aquí estoy amplia, tengo patio. En una casa que me den no voy a estar así... si me dejan aquí, yo misma puedo arreglarla y ponerla bonita también. (Larisa)

Para nuestros interlocutores, la posibilidad de renovar gradualmente el espacio construido a través del tiempo, les permite proyectar sus aspiraciones de permanencia tanto en el campamento como en Chile; deseos y proyecciones que se articulan a partir del proceso de autoconstrucción y que difícilmente podrían forjarse ante las dificultades de vivir de arrendatario. En ese sentido, más que un derrotero ineludible hacia la marginalidad, el espacio del campamento se encuentra en constante construcción, proyección y disputa por parte de sus habitantes, quienes manifiestan un deseo de integración a la sociedad a través de la construcción/urbanización de la ciudad. 


\section{Reflexiones finales}

A lo largo de este artículo, hemos cuestionado el carácter problemático que presenta la llegada de migrantes latinoamericanos a los campamentos. Como se ha visto, buena parte de dicho carácter, y de la presencia de migrantes en ellos, reposa sobre nociones teóricas que parecen dominar el debate académico. Mientras algunos enfoques examinan los asentamientos informales como espacios marginales que impiden las posibilidades de integración de sus residentes, otros miran a la concentración de migrantes en áreas específicas de la ciudad como una señal inequívoca de segregación etnonacional y potenciales indicios de guetificación.

Bajo la consideración de que el poblamiento informal y la concentración de grupos migrantes en determinadas áreas no es resultado único de la exclusión, sino también de la agencia y las capacidades de creación y reclamo espacial de sus habitantes, en este artículo hemos propuesto una explicación alternativa al "problema" del campamento. Como primer punto, hemos planteado que el núcleo problemático que enfrentan los migrantes latinoamericanos al momento de acceder a una vivienda está relacionado con las características que adquiere el proceso de arrendamiento y la serie de dificultades asociadas, como son los elevados precios, la inseguridad en la tenencia, las relaciones hostiles con los arrendadores y la inadecuación de las viviendas a las aspiraciones, necesidades y proyectos familiares.

En ese marco, como segundo punto, afirmamos que, antes que únicamente un problema, el campamento emerge también como una alternativa efectiva frente a las dificultades generadas por las dinámicas de arriendo. A diferencia de la vivienda en arriendo, de acuerdo a los discursos de nuestros informantes, el campamento permite reducir gastos, otorga un mayor sentido de seguridad y da pie a un proceso de mejora continua de los espacios habitados que, eventualmente, podrían materializar condiciones consideradas adecuadas para "vivir bien". Sumado a ello, el proceso de autoconstrucción de la vivienda permite articular aspiraciones de permanencia e integración que, aunque fragmentarias y sin dar cuerpo a un reclamo colectivo por integración, hacen posible la imaginación de una vida futura en Chile.

Si las lecturas teóricas y políticas predominantes han pensado el hábitat informal casi exclusivamente como espacios de pobreza y exclusión, la presencia de migrantes en campamentos nos invita a reevaluar estas visiones y a reconsiderar el papel de constructores de ciudad de estos nuevos habitantes de los campamentos. Para ello, resulta primordial considerar, como acotaran Grignon y Passeron (1991), que ninguna condición social, por más degradada que sea, puede impedir completamente el trabajo de organización simbólica. Tomar en cuenta aquellos "simbolismos irreductibles" presentes en las maneras de pensar el campamento, la autoconstrucción y las aspiraciones de permanencia e integración de los migrantes no implica idealizarlos o asumir una forma de romanticismo. Más bien, es una necesaria restitución de una perspectiva alternativa a aquellas que, durante décadas, han sobrealimentado las lecturas miserabilistas en la teoría social.

De este modo, y con el mismo espíritu, creemos que los elementos emergentes de este fenómeno nos compelen a replantear los 
abordajes de la política pública en materia de soluciones habitacionales. Ante esto surgen algunas preguntas: ¿es la erradicación de campamentos la única solución posible para resolver el problema de la vivienda entre migrantes? ¿Tiene la condición informal de la ocupación un carácter fijo y permanente o, en cambio, puede la presencia de migrantes en campamentos permitir la articulación de nuevas demandas reivindicativas que reviertan dicha nomenclatura? Este último aspecto tiene un largo antecedente en América Latina. Como señala Caldeira (2017), la informalidad no está inscrita en el destino de los asentamientos de la

\section{Notas}

\footnotetext{
${ }^{1}$ Una excepción a esta tendencia es el estudio de Brain, Prieto y Sabatini (2010), quienes explican la persistencia de los campamentos como una estrategia de familias pobres - menos organizadas que en el pasado y con mayor riesgo de ser segregadas por las políticas de viviendas- para acceder a una mejor localización en la ciudad.

${ }^{2}$ Para asegurar la privacidad de nuestros interlocutores, usamos seudónimos para los entrevistados que aparecen en este artículo. El nombre del campamento, sin embargo, es real.
}

\section{Referencias bibliográficas}

Abufhele, V. (2019). La política de la pobreza y el gobierno de los asentamientos informales en Chile. Revista EURE - Revista de Estudios Urbano Regionales, 45(135), 49-69.

Adler-Lomnitz, L. (1977). Networks and marginality: Life in a Mexican shantytown. Nueva York: Academic Press.

Alexander, C. (2011). Making Bengali brick lane: claiming and contesting space in East London. British Journal of Sociology, 62(12), 201-220.

Angelcos, N. \& Pérez, M. (2017). De la "desaparición" a la reemergencia: continuidades y rupturas del movimiento de pobladores en Chile. Latin American Research Review, 52(1), 94-109.

Boltanski, L. (2012). De la crítica: compendio de sociología de la emancipación. Madrid: Akal.

Bonilla, F. (1970). Rio's favelas: The rural slum within the city. En Mangin, W. (Ed.), Peasants in cities: Reading in the anthropology periferia urbana, sino que su carácter depende, en gran medida, de la voluntad política de los actores institucionales y la fuerza negociadora de los propios ciudadanos. En ese sentido, antes que un derrotero ineludible de exclusión social, la presencia de migrantes en campamentos en Chile invita a discutir la noción misma de la informalidad y a elaborar nuevas soluciones políticas que permitan una integración que se haga cargo de las aspiraciones y los aportes de los migrantes latinoamericanos a la ciudad y la sociedad. Para ello, la participación de dichos actores en la esfera pública resulta tan necesaria como urgente.

\footnotetext{
${ }^{3}$ Siguiendo a Saba Mahmood (2012), entendemos por agencia una "capacidad para la acción que relaciones específicas de subordinación crean y permiten" (p.18). Al ser parte fundamental de los procesos de formación ética y política, dicha capacidad está históricamente situada, lo cual no implica, necesariamente, la elaboración de un proyecto de transformación social. En ese sentido, anclamos la agencia de los migrantes en sus prácticas de autoconstrucción, en la medida en que dicha performance les permite proyectar sus anhelos de integración y permanencia.

${ }^{4}$ Ver, por ejemplo, la discusión sobre el rol de la autoconstrucción en el movimiento de pobladores (Angelcos \& Pérez, 2017).
}

of urbanization (pp. 72-84). Boston: Houghton Mifflin Company.

Brain, I., Prieto, J. \& Sabatini, F. (2010). Vivir en campamentos: ¿Camino hacia la vivienda formal o estrategia de localización para enfrentar la vulnerabilidad? Revista EURE - Revista de Estudios Urbano Regionales, 36(109), 111-141.

Caldeira, T. (2017). Peripheral urbanization: Autoconstruction, transversal logics, and politics in cities of the global south. Society and Space, 35(1), 3-20.

Campos, K. (2017). Inmigración en campamentos, percepciones sobre la vida en asentamientos precarios de Copiapó. Revista Centro de Investigación Social, 22, 109-129.

Castells, M. (1983). The city and the grassroots: A cross-cultural theory of urban social movements. Berkeley: University of California Press.

CIS-TECHO (2015). Datos duros de una realidad más dura: Informe 
Encuesta Nacional de Campamentos 2015. Santiago: TECHO-Chile. (2018). Campamentos sin fronteras: Migración extranjera en campamentos de Antofagasta. Santiago: TECHO-Chile.

Contreras, Y., Ala-Louko, V. \& Labbé, G. (2015). Acceso exclusionario y racista a la vivienda formal e informal en las áreas centrales de Santiago e lquique. Polis, 14(42), 53-78.

Curahua, D. (2013). Integración social y protección de los derechos humanos de los migrantes. En Migraciones: Conferencia Internacional sobre Migraciones y Derechos Humanos: Estándares y Prácticas (pp. 43-48). Santiago: Aún Creemos en los Sueños.

Ducci, M. (1997). Chile: el lado oscuro de una política de vivienda exitosa. Revista EURE - Revista de Estudios Urbano Regionales, 23 (69), 99-115.

Dromi, R. (1987). Derecho urbanístico argentino. Conferencia pronunciada en el Instituto de Estudios de Administración Local (IEAL), Madrid.

Espinoza, V. (1988). Para una historia de los pobres de la ciudad. Santiago: SUR.

Fassin, D. (2015). La economía moral del asilo: Reflexiones críticas sobre la "crisis de los refugiados" de 2015 en Europa. Revista de Dialectología y Tradiciones Populares, LXX(2), 277-290

Garcés, A. (2014). Comercio ambulante, agencia estatal y migración: Crónica de un conflicto en Santiago de Chile. En Imilan, W., Garcés, A. \& Margarit, D. (Eds.), Poblaciones en movimiento: Etnificación de la ciudad, redes e integración (pp. 147-166). Santiago: Universidad Alberto Hurtado.

Glaser, B. \& Strauss, A. (2017). The discovery of grounded theory: Strategies for qualitative research. Nueva York: Routledge.

Geertz, C. (1989). El antropólogo como autor. Barcelona: Paidós.

Giusti, J. (1973). Organización y participación popular en Chile: El mito del "hombre marginal". Santiago: Facultad Latinoamericana de Ciencias Sociales.

Grignon, C. \& Passeron, J. (1991). Lo culto y lo popular: Miserabilismo y populismo en sociología y literatura. Buenos Aires: Nueva Visión.

Holston, J. (2008). Insurgent citizenship: Disjunctions of democracy and modernity in Brazil. Princeton: Princeton University Press.

INE (2018). Síntesis de resultados CENSO 2017. Instituto Nacional de Estadísticas, Gobierno de Chile. Recuperado de https://www. censo2017.cl/descargas/home/sintesis-de-resultados-censo2017.pdf

Imilan, W., Garcés, A. \& Margarit, D. (Eds.). (2014). Poblaciones en movimiento: Etnificación de la ciudad, redes e integración. Santiago: Universidad Alberto Hurtado.

Jiménez, E. (2016). Inmigrantes negros en la población Los Nogales de Estación Central: El preludio de un gueto. En Tijoux, M. E. (Ed.), Racismo en Chile: La piel como marca de la inmigración (pp. 141-159). Santiago: Universitaria.

Lefebvre, H. (1996). Writings on cities. Cambridge: Wiley-Blackwell.

López-Morales, E., Flores, P. \& Orozco, H. (2018). Inmigrantes en campamentos en Chile: ¿Mecanismo de integración o efecto de exclusión? Revista INVI, 33(94), 159-185.

Mahmood, S. (2012). Politics of piety: The islamic revival and the feminist subject. Princeton: Princeton University Press.

Mangin, W. (1967). Latin American squatter settlements: A problem and a solution. Latin American Research Review, 2(3), 65-98.

Margarit, D. \& Bijit, K. (2014). Barrios y población migrante: El caso de la comuna de Santiago. Revista INVI, 29(81), 19-77.

Margarit, D. \& Galaz, C. (2018). Espacios barriales y convivencia: Reflexiones sobre las concentraciones de población inmigrada y la territorialidad urbana. Revista Rumbos, 17, 23-50.

Márquez, F. (2004). Márgenes y ceremonial: Los pobladores y la política de vivienda social en Chile. Política (43),185-203.

(2014). Inmigrantes en territorios de frontera: La ciudad de los otros: Santiago de Chile. Revista EURE - Revista de Estudios Urbano Regionales, 4O(120), 49-72.

Matos Mar, J. (1984). Desborde popular y crisis del Estado. Lima: Instituto de Estudios Peruanos.

Ministerio de Vivienda y Urbanismo (2019). Catastro nacional de campamentos. Gobierno de Chile. Recuperado de https://www. minvu.cl/wp-content/uploads/2019/12/Presentaci\%C3\%B3n-deResultados.pdf

Mora, C. (2008). Globalización, género y migraciones. Polis, 7(20), 285-297.

Morales, R., Besoain, C., Soto, A., Pinto, L., Hidalgo, K., Fernández I. \& Bernal, V. (2017). Retorno al campamento: resistencia y melancolía en los márgenes de la ciudad formal. Revista INVI, 30(90), 51-75.

Pavez, I. (2012). Inmigración y racismo: Experiencias de la niñez peruana en Santiago de Chile. Si Somos Americanos, 12(1), 75-99.

Perissinotti, M. (2016). Un lugar donde vivir: Las luchas migrantes por el acceso al espacio urbano en la ciudad de Córdoba (Argentina). EMHU-Revista Interdisciplinar da Mobilidade Humana, XXIV(47), 59-76.

PerIman, J. E. (1976). The myth of marginality: Urban poverty and politics in Rio de Janeiro. Berkeley: University of California Press.

Piña, L. (2010). Calle y casa: Aportes teóricos para una comprensión de la situación de calle desde sus actores. Polis, 9(26), 315-336.

Rivas, A. (2013). Estrategias residenciales y procesos de recomposición familiar. Papers, 98(1), 103-126.

Sheehan, M. (2018). Migrant residents in search of residences: Locating structural violence at the interstices of bureaucracies. Conflict and Society, 4(1), 151-166.

Skewes, J. (2005). De invasor a deudor: El éxodo desde los campamentos a las viviendas sociales en Chile. En Rodríguez, A. \& Sugranyes, A. (Eds.). Los con techo: Un desafío para la política de vivienda social (pp. 101-122). Santiago: SUR.

Soto, H. de (1987). El otro sendero: la revolución informal. Buenos Aires: Sudamericana.

Staab, S. \& Maher, K. H. (2006). The dual discourse about Peruvian domestic workers in Santiago de Chile: Class, race, and a nationalist project. Latin American Politics and Society, 48(1), 87-116.

Stefoni, C. \& Fernández, R. (2011). Mujeres inmigrantes en el trabajo doméstico: Entre el servilismo y los derechos. En Stefoni, C. 
(Ed.), Mujeres inmigrantes en Chile: ¿Mano de obra o trabajadoras con derechos? (pp. 43-72). Santiago: Universidad Alberto Hurtado.

Tapia, M. (2012). Frontera y migración en el norte de a partir del análisis de los censos población: Siglos XIX- XXI. Revista de Geografía Norte Grande (53), 177-198.

Thayer, E. (2013). Expectativas de reconocimiento y estrategias de incorporación: La construcción de trayectorias degradadas en migrantes latinoamericanos residentes en la Región Metropolitana de Santiago. Polis, 12(35), 259-285.

Tijoux, M. E. (2013). Niños(as) marcados por la inmigración peruana: Estigma, sufrimientos, resistencias. Convergencia, 20(61), 83-104.

Tonkiss, F. (2005). Space, the city and social theory. Cambridge: Polity Press.

Turner, J. (1968). Housing priorities, settlement patterns, and urban development in modernizing countries. Journal of the American Institute of Planners, 34(6), 354-363.
Valdebenito, F. \& Guizardi, M. L. (2015). Espacialidades migrantes: Una etnografía de la experiencia de mujeres peruanas en Arica (Chile). Gazeta de Antropología, 31(1). Recuperado de http://www.gazeta-antropologia.es/?p=4661

Varley, A. (2013). Postcolonialising informality? Society and Space, (31), 4-22.

Vekemans, R. (1966). Marginalidad y promoción popular. Santiago: DESAL.

(1969). Marginalidad en América Latina: Un ensayo de conceptualización. Santiago: DESAL.

Vekemans, R., Giusti, J. \& Silva, I. (1970). Marginalidad, promoción popular e integración latinoamericana. Santiago: DESAL.

Wirth, L. (1982). The ghetto. Chicago: University of Chicago Press. 